\title{
Vascular complications in adults and pediatrics Live-donor renal transplantation: 3-Decades of single Centre experience
}

\author{
Ahmed Shokeir, Nabil Hassan, Mohamed Kamal, Shady Soliman and M. A. Ghoneim \\ Mansoura Urology \& Nephrology Center, Mansoura University, Mansoura, Egypt.
}

\begin{abstract}
We analyzed the incidence of vascular complications in adults and pediatrics live donor renal transplantations over 3-decades and compared its impact upon patient and graft survival in both groups.

Material and methods: Between March 1976 and December 2005, 1785 live-donor renal transplants were performed in a single institute, of the 1546 adults and 239 pediatric (age $\leq 18$ years). The incidence of different types of vascular complications were determined in both groups. Long term patient and graft survival in patients with or without vascular complications and in various types of vascular complications were calculated \& compared in both groups.

Results: The overall incidence of vascular complications was $2.9 \%$, it was equally $2.9 \%$ in both groups. In adults, 46 complications in 45 patients included 16 arterial, 10 renal artery thrombosis $(0.6 \%), 2$ cases of spasm in renal artery $(0.1 \%)$, renal artery stenosis in $5(0.3 \%)$, renal vein thrombosis in one $(0.06 \%)$ and hemorrhagic complications in 28 patients where as there were no thrombotic complications in the pediatric group, 6 case of hemorrhage $(2.5 \%)$ and one case of renal artery stenosis $(0.4 \%)$. There is steady decrease of vascular complications over the last 3 decades. The vascular complications significantly adverse patient and graft survival in both groups $(\mathrm{p}<0.001)$.
\end{abstract}

Correspondence and offprint requests to: Dr. Nabil Hassan, Mansoura Urology and Nephrology Center, Mansoura University, Mansoura, Egypt.
The 5-years patient and graft survival in adults and pediatrics with or without vascular complications were $59.5 \pm 9.2 \%, 89.14 \pm 0.89 \%, 57.5 \pm 18.7 \%$ and $90.18 \pm 2.2 \%$ for the patient and $40.14 \pm 7.75 \%$, $97.79 \pm 1.14 \%, 28.57 \pm 17.07 \%$ and $77.18 \pm 3.02 \%$ for the graft. There is no statistical significant difference in either patient or graft survival in thrombotic, stenotic or hemorrhagic complications in adult or hemorrhagic complications in the pediatric group. ( $\mathrm{p}=0.22$ and $\mathrm{p}=0.142$ respectively). Conclusions: There is no increase in incidence of vascular complications in pediatrics than adult transplants. The survival either graft or patient is comparable between adult and pediatric with or without vascular complications and the subgroups of vascular complications.

\section{Introduction}

The treatment of choice for patients with end-stage renal disease is renal transplantation. Live-donor renal transplantation has better graft and patient survival than cadaver [1,2], because it is precious, it should be continuously monitored to detect and manage any complications. Vascular complications have negative impact on patient and graft survival [3]. The incidence of vascular complications is higher in cadaver than live donor transplants as live donor renal transplantation is performed in more favorable conditions.Vascular complications is discussed in the literature in large number of publications, most of them belong to the cadaver [4], little in live donor [3]. We analyzed the incidence of vascular complications in adults and 
pediatrics live donor renal transplantations over 3decades and compared its impact upon patient and graft survival in both groups.

\section{Material and methods}

Between March 1976 and December 2005, a total of 1785 live-donor renal transplants were performed in a single institute, they were 1546 adults and 239 pediatrics (age $\leq 18$ years). In the adult group the mean age was $32.4 \pm 8$ year (range 19 to 62 years) whereas it was $14.12 \pm 3.38$ years (range 5-18 years) in the pediatric group.

Operative technique: The graft was revascularized in standard fashion. In the adult group, the main renal artery was anastmosed to internal iliac artery in 1417 patients, to external iliac artery in 105 patients, to common iliac artery in 20 patients and to aorta in one patient, whereas the renal vein anastmosed to external iliac vein in 1515 pateints, common iliac in 20 patients and IVC in 9 patients. In the pediatric group, the renal artery was anastomosed to internal iliac in 159 patients, external iliac in 4 patients, common iliac in 65 patients and aorta in 11 patients. The renal vein was anastomoed to external iliac vein in 136 patients common iliac in 6 while to IVC in 97 patients.

The vascular ischemia time was $45.01 \pm 13,78$ minutes (range 18-132min) in adult group, while it was $48.89 \pm 15.49$ minutes in pediatric group .Table 1 list technical variables of vascular anastomosis in both groups. Several immunosuppressive regimens were used throughout this period (table 1).

Postoperative work-up: After surgery the patients were monitored clinically, biochemically and radiologically. Different modalities were used to diagnose a vascular complication. When cases of renal artery stenosis or thrombosis were suspected clinically, Doppler ultra-sound, magnetic resonance angiography and conventional angiography were performed to confirm the diagnosis. Cases of hemorrhage were diagnosed by clinical observation, while haematoma was detected by gray-scale ultrasound and confirmed by computerized tomography and magnetic resonance imaging with or without aspiration of perigraft collections. Data were stored in an electronic data base.

Statistical analysis: To determine the statistical significance of differences the Pearson and chi- square tests were used. Survival of grafts and patients was calculated using the Kaplan-Meier technique. Differences in survival were calculated by the $\log$ rank test with $\mathrm{p}<0.05$ considered significant

\section{Results}

The over all incidence of vascular complications was $2.9 \%$, it was equally $2.9 \%$ in both groups. There were complications in 45 adult patients included 17 arterial complications, 10 renal artery thrombosis $(0.6 \%), 2$ cases of spasm in renal artery $(0.1 \%)$ renal artery stenosis in $5(0.3 \%)$, renal vein thrombosis in one patient $(0.06 \%)$ and haemorrhagic complications in 28 patients $(1.8 \%)$ while in pediatric group, there was no cases of either renal artery or vein thrombosis, 6 cases of hemorrhage $(2.5 \%)$ and one case of renal artery stenosis $(0.4 \%)$.

The incidence of vascular complications was correlated to various pretransplant, technical and post transplant variables (table 1). One uni-varaite analysis, the female Gender, arterial anastomosis to external iliac artery had higher complications in adult group as well as age 5-10 year in pediatric. ATN is statistically significant higher in both groups of complications than normal $(\mathrm{p}<0.001)$

The time of occurrence, main presenting symptoms the primary method for diagnosis, management and prognosis of our complications are displayed in table 2.

The vascular complications significantly adverse patient and graft survival in both groups $(\mathrm{p}<0.001)$. The 5-years patient survival in adults and pediatrics with or without vascular complications were $59.5 \pm 9.2 \%, \quad 89.14 \pm 0.89 \%, \quad 57.5 \pm 18.7 \%$ and $90.18 \pm 2.2 \%$ for the patient. The 5-years graft survival was $40.14 \pm 7.75 \%$, $97.79 \pm 1.14 \%$, $28.57 \pm 17.07 \%$ and $77.18 \pm 3.02 \%$ for the same groups. There is no statistical significant difference in either patient or graft survival in thrombotic, stenotic or hemorrhagic complications in adult or hemorrhagic complications in the pediatric group. ( $\mathrm{p}=0.22$ and $\mathrm{p}=0.142$ respectively).

The long term graft and patient survival in patients with or without vascular complications are displayed in table 3 and 4 \& figures 1 and 2 whereas the long term graft and patient survival in relation to various causes of vascular complications are displayed in tables 5 and $6(\mathrm{P}=0.142 \& \mathrm{P}=$ 0.222 respectively). 
Table 1. Univariate analysis of different pre-transplant, technical \& post transplant possible risk factors for vascular complications

\begin{tabular}{|c|c|c|c|c|}
\hline & Adult/comp. $(\%)$ & $P$ Value & Pediatricl/Comp. (\%) & $P$ value \\
\hline & \multicolumn{4}{|c|}{ Pre transplant } \\
\hline \multicolumn{5}{|l|}{ Recipient age } \\
\hline $5-10$ & & & $37 / 3(8.1)$ & \\
\hline $10-15$ & & & $97 / 4(4.1)$ & 0.02 \\
\hline $15-18$ & & & $105 /-$ & \\
\hline $18-20$ & $86 / 101.2)$ & & & \\
\hline $20-$ & $648 / 13(2)$ & & & \\
\hline $30-$ & $520 / 21(4)$ & 0.18 & & \\
\hline $40-$ & 248/10 (4) & & & \\
\hline $50-$ & $44 / 1(2.3)$ & & & \\
\hline \multicolumn{5}{|l|}{ Recipient sex } \\
\hline Male & $1175 / 28(2.4)$ & 0.014 & $153 / 4(2.6)$ & \\
\hline Female & $371 / 18(4.9)$ & & $86 / 3(3.5)$ & 0.7 \\
\hline \multicolumn{5}{|l|}{ Donor age } \\
\hline$<30$ & $658 / 27(4.1)$ & & $47 / 0$ & \\
\hline $30-$ & $469 / 11(2.3)$ & 0.102 & $107 / 3(2.8)$ & 0.24 \\
\hline $40-$ & $281 / 7(2.5)$ & & $67 / 4(6)$ & \\
\hline $50-$ & 138/1 (0.7) & & $18 / 0$ & \\
\hline \multicolumn{5}{|l|}{ Donor Sex } \\
\hline Male & $775 / 27(3.5)$ & 0.23 & $83 / 4(4.8)$ & \\
\hline Female & $771 / 19(2.5)$ & & $156 / 3(1.9)$ & 0.206 \\
\hline \multicolumn{5}{|l|}{ HLA mismatch } \\
\hline Zero match & $120 / 2(1.7)$ & & $3 /-$ & \\
\hline One & 264/11 (4.2) & & $26 / 3(11.5)$ & 0.02 \\
\hline Two & $786 / 23(2.9)$ & 0.84 & $169 / 3(1.8)$ & \\
\hline Three & 196/7 (3.6) & & $32 /-$ & \\
\hline \multirow[t]{2}{*}{ Four } & $136 / 2(1.5)$ & & & \\
\hline & \multicolumn{4}{|c|}{ Technical } \\
\hline \multicolumn{5}{|c|}{ No of renal arteries } \\
\hline Single & $1375 / 39(2.8)$ & & $215 / 7(3.3)$ & 0.36 \\
\hline Multiple & $171 / 7(3.4)$ & 0.89 & $24 /-$ & \\
\hline \multicolumn{5}{|l|}{ Main renal artery } \\
\hline Int. iliac & $1417 / 38(2.7)$ & & $156 / 3(1.9)$ & \\
\hline Extra iliac & $105 / 8(7.6)$ & 0.037 & $4 /-$ & 0.32 \\
\hline Common iliac & $23 /-$ & & $61 / 4(6.2)$ & \\
\hline Aorta & $1 /-$ & & $11 /-$ & \\
\hline \multicolumn{5}{|c|}{ Ischemia time (min) } \\
\hline$<30$ & $195 / 3(1.5)$ & & $24 /-$ & \\
\hline $30-60$ & $1192 / 40(3.4)$ & 0.27 & $176 / 5(2.8)$ & 0.49 \\
\hline$>60$ & $154 / 3(1.9)$ & & $39 / 2(5.1)$ & \\
\hline \multicolumn{5}{|l|}{ Time to diuresis } \\
\hline Immediate & $1428 / 38(2.7)$ & & $205 / 5(2.4)$ & 0.27 \\
\hline Delayed & $116 / 8(6.9)$ & 0.009 & $34 / 2(5.9)$ & \\
\hline
\end{tabular}




\begin{tabular}{|c|c|c|c|c|}
\hline \multicolumn{5}{|l|}{$A T N$} \\
\hline No & $1468 / 35(2.4)$ & & 224/5 92.2) & \\
\hline Yes & 78/11(14.1) & 0.00001 & $15 / 2913.3)$ & 0.013 \\
\hline \multicolumn{5}{|l|}{ Transplant received } \\
\hline First & $1478 / 43(2.9)$ & & $235 / 7(3)$ & \\
\hline Second & $66 / 3(4.5)$ & 0.72 & $4 /-$ & 0.72 \\
\hline \multirow[t]{2}{*}{ Third } & $2 /-$ & & & \\
\hline & \multicolumn{4}{|c|}{ Post transplant } \\
\hline \multicolumn{5}{|l|}{ Acute rejection } \\
\hline No & $909 / 26(2.9)$ & & $131 / 3(2.3)$ & \\
\hline Yes & $637 / 20(3.1)$ & 0.7 & $107 / 4(3.7)$ & 0.51 \\
\hline \multicolumn{5}{|l|}{ Immunosupp. regimens } \\
\hline Steroid + Aza & $280 / 10(3.5$ & & $20 / 2(10)$ & \\
\hline Steroid + CsA & $143 / 10(6.9)$ & & $30 / 2(6)$ & \\
\hline Steroid + CsA+Aza & $741 / 18(2.4)$ & & $139 / 1(0.7)$ & \\
\hline St+sirolimus(MMf/FK) & $2 /-$ & 0.26 & $3 /-$ & 0.23 \\
\hline Others & $248 / 8(3.2)$ & & $47 / 2(4.2)$ & \\
\hline \multicolumn{5}{|l|}{ Transplant are } \\
\hline $1976-1985$ & $127 / 7(5.5)$ & & $17 /-$ & \\
\hline 1986-1995 & $654 / 18(2.8)$ & 0.21 & $92 / 4(4.3)$ & 0.51 \\
\hline $1996-2005$ & $765 / 21(2.7)$ & & $130 / 3(2.3)$ & \\
\hline
\end{tabular}

Table 2. Diagnosis, management \& outcome of vascular complication

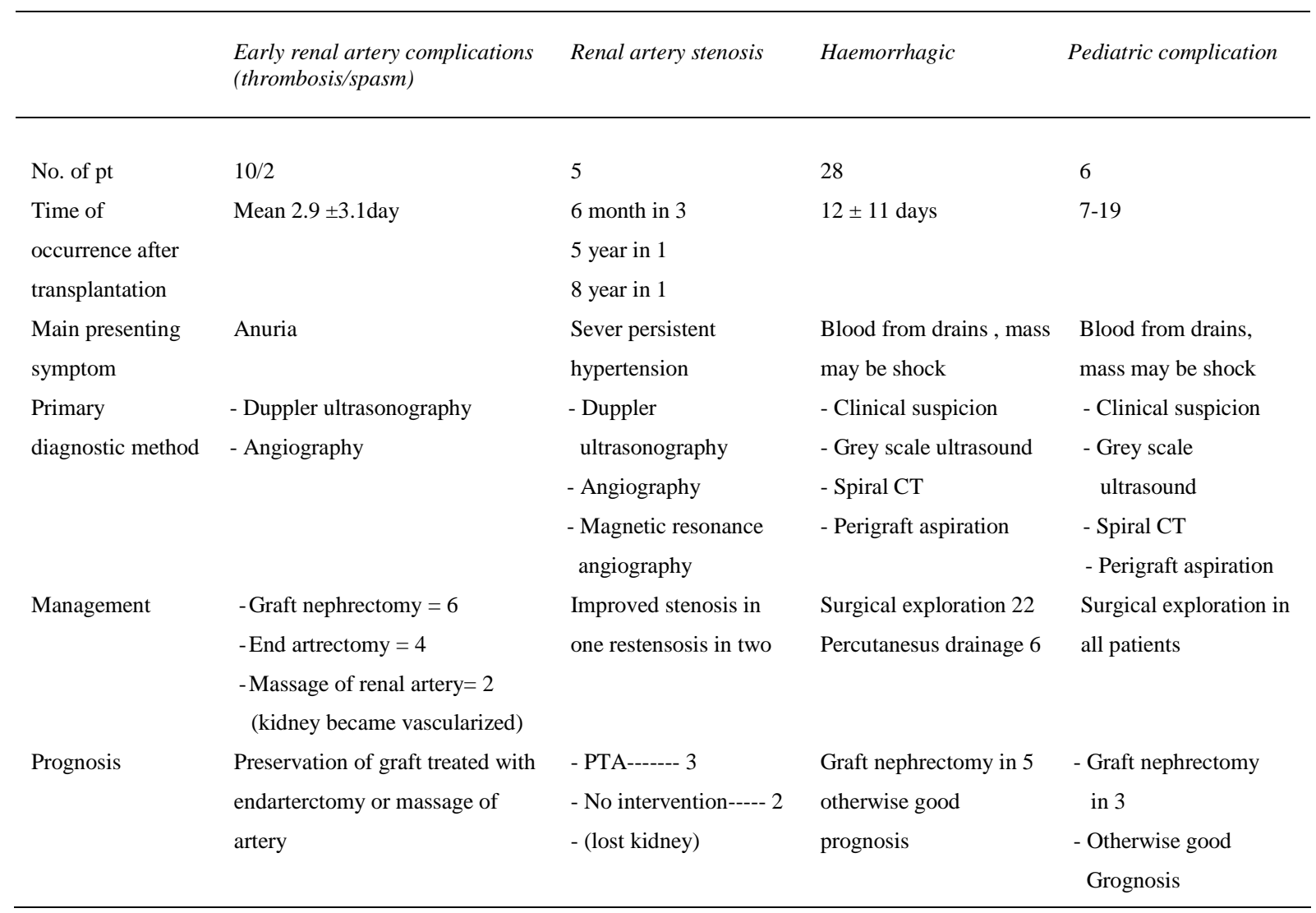


Table 3. Long-term graft survival in pediatric and adult renal transplants

\begin{tabular}{lllll}
\hline & 5- year & SE & 10- year & SE \\
\hline Pediatrics with vascular complications & 28.57 & 17.07 & 28.57 & 17.07 \\
Adults with vascular complications & 40.14 & 7.75 & 19.62 & 7.68 \\
Pediatrics without vascular complications & 77.18 & 3.02 & 47.11 & 4.36 \\
Adults without vascular complications & 79.79 & 1.14 & 55.29 & 1.66 \\
& & & & \\
\hline
\end{tabular}

$\mathrm{p}<0.001$

Table 4. Long-term patient survival in pediatric and adult transplants

\begin{tabular}{lllll}
\hline & 5-year & SE & 10-year & SE \\
\hline Pediatrics with vascular complications & 57.5 & 18.7 & 57.5 & 18.7 \\
Adults with vascular complications & 59.5 & 9.2 & 29.09 & 10.84 \\
Pediatrics without vascular complications & 90.18 & 2.22 & 76.15 & 4.11 \\
Adults without vascular complications & 89.14 & 0.89 & 78 & 1.52 \\
\hline
\end{tabular}

$\mathrm{p}<0.001$

Table 5. Long-term graft survival in various type of vascular complication

\begin{tabular}{lllll}
\hline & 5- year & SE & 10- year & SE \\
\hline Stenotic complications & 80.0 & 7.89 & 60 & 21.91 \\
Thrombotic complications & 19.23 & 15.18 & 19.23 & 15.18 \\
Hemorrhagic complications & 40.02 & 9.8 & 15.01 & 8.9 \\
Vasclar complications in pediaterics & 28.57 & 17.07 & 14.29 & 13.23 \\
& & & & \\
\hline
\end{tabular}

$P=0.142$

Table 6. Long-term patient survival in various type of vascular complication

\begin{tabular}{lllll}
\hline & 5- year & SE & 10- year & SE \\
\hline Stenotic complications & 100 & 0 & 75 & 21 \\
Thrombotic complications & 58.33 & 25.06 & 58.33 & 25.06 \\
Hemorrhagic complications & 49.9 & 10.91 & 18.71 & 10.9 \\
Vasclar complications in pediaterics & 57.14 & 18.7 & 57.14 & 18.7 \\
& & & & \\
\hline
\end{tabular}

$\mathrm{P}=0.222$ 


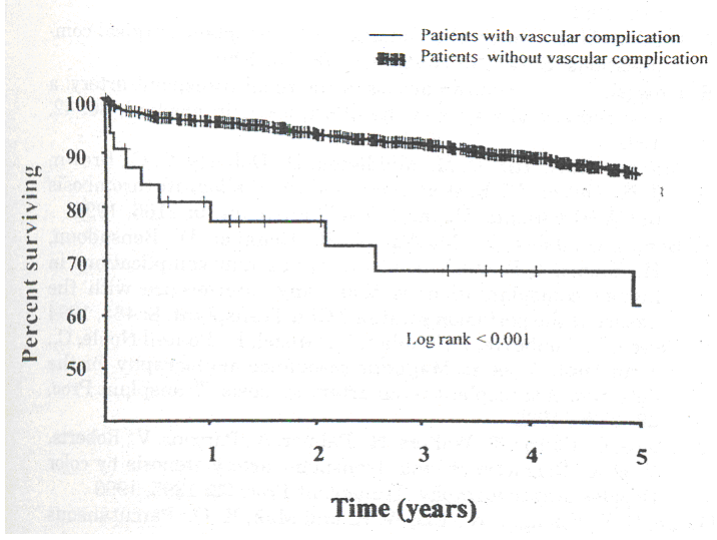

Fig. 1. Ssurvival of patients with and without vascular complications $(\mathrm{P}<0.001)$.

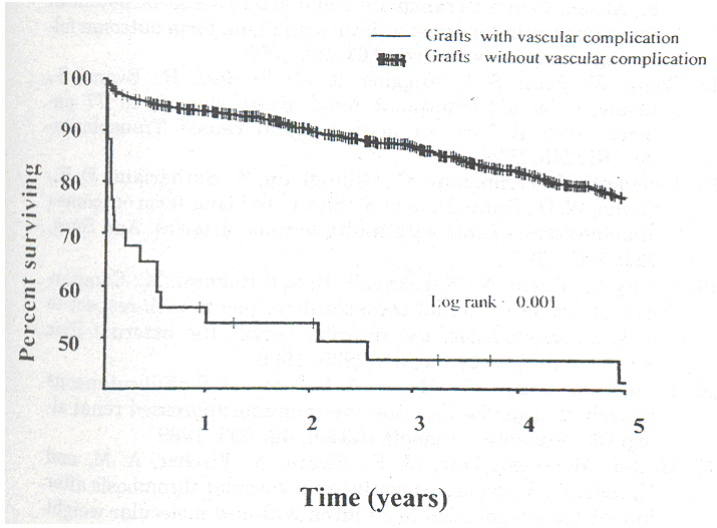

Fig. 2. Graft survival of patients with and without vascular complications $(\mathrm{p}<0.001)$.

\section{Discussion}

Over the past three decades, the rate of complications following kidney transplantation has decreased due to improvements in surgical and diagnostic techniques, as well as to the greater safety of the immunosuppressive regimens. The incidence of vascular complications was reportedly as high as $30 \%$ during the early stages of development of the transplant procedure [5]. currently the incidence ranged from 0.8 to $6 \%$ [6]. Arterial complications are more frequent and more dangerous than venous misadventures.

Several mechanisms causing vascular thrombosis have been addressed such as faulty suture technique producing incomplete intimal re-approximation with secondary intraluminal fibrosis, postoperative hypotension, hypercoagulable state, atherosclerosis of the donor or recipient vessels, trauma to the donor artery during perfusion, wide disparity in vessel size, torsion of the graft during performance of the anastomosis, kinking of artery and angulation of the vein owing to improper location of the graft or to the anastomosis $[5,7]$.

In the present series, the overall incidence of renal artery thrombosis was $0.5 \%$, it was $0.6 \%$ in adult which is similar to our previous report [3] while we were not confronted with either renal artery or vein thrombosis in the pediatric group, this may be explained by meticulous vascular anastomosis by well-trained highly specialized urologists and our routine policy of one week post -transplantation heparinization while in the adult the issue of heparinizaion is controversial, heparin was found to decrease thromboembolic complications without an impact upon lymph drainage or bleeding sequels [8]. Two different group of investigators showed that LMWH can reduce or even abolish the thrombotic sequels without increase in postoperative surgical bleeding $[9,10]$, Humar et al., denied the necessity of anticoagulation for nonrisky renal transplants and advised to restrict a short course of heparinization only for risky patients [11]. Recently in our institute we finished a prospective randomized study included 75 patients randomized between three arms one group did not received any anticoagulants, other receive conventional unfractionated heparin and the third group received LMWH in non risky renal transplants, and we concluded that post-operative heparin administration in non-risky live donor renal transplantation is associated by significant drop in the hemoglobin level as well as prolonged and excessive lymph drainage without improvement in graft outcome and should not be a routine in nonrisky live-donor renal transplantation [12].

Graft renal artery stenosis occur in a range of 0.8 to $12.4 \%$ of all renal transplants $[13,14]$. The stenosis may be located before the anastomosis (because of atherosclerotic disease in the donor vessel), at the anastomosis (secondary to vessel perfusion injury, faulty suture technique, or reaction to suture material), or after the anastomosis (due to rejection, turbulent flow from kidney malposition, or arterial twisting, kinking, or compression). Immunological injury is also proposed as the possible cause. Approximately half of renal artery stenoses occur at the anastomosis [15,16]. The gold standard for diagnosing stenosis still remains renal angiography [15]. Duplex-Doppler examination, performed by an experienced operator, is an invaluable tool for the diagnosis and follow-up of a stenosis [17]. Magnetic resonance imaging (MRI) can be considered a safe and non-invasive alternative to angiography [18].

The low incidence of renal artery stenosis in adult 
and pediatrics $(0.3 \%$ and $0.4 \%)$ in our serious and in our previous report $0.4 \%$ [3], though we used the internal iliac artery in arterial anastmosis in large proportion of our patients, could be attributed to the wide spatulation we made in both graft and internal iliac arteries, the procedure was done by highly specialized surgeons under strict supervision of the whole cohort of patients by single surgeon (G.M.A.) A stenosis could be treated conservatively or by revascularization. Revascularization can be surgical or by percutaneous transluminal renal angioplasty (PTRA) $[15,19]$. Surgical correction of graft renal artery stenosis is usually successful, but it is associated with substantial morbidity [19]. Primary treatment of graft renal artery stenosis by means of percutaneous transluminal angioplasty with or without stent placement results in good intermediate-term patency and is associated with significant early improvement in blood pressure and creatinine level [20]. Because of its low level of morbidity, relatively modest cost, and effectiveness, percutaneous transluminal angioplasty is accepted as the initial treatment of choice [20].

Although early bleeding from either the arterial or the venous anastomosis is rare, it is not unusual for end-stage renal disease patients to display a bleeding diathesis caused by defective coagulation due to platelet dysfunction or altered intravascular coagulation.. Hemorrhage within the first week can occur due to graft rupture from an uncontrolled accelerated rejection process. After one month posttransplant, the most common cause of hemorrhage is mycotic infection of the anastomosis [21].

There is slight but not statistically significant increase the hemorrhagic complications in pediatric $(2.5 \%)$ than adult $(1.8 \%)$.this is lower than $3.86 \%$ reported by kocak et al 2004, this may be attributed to the routine heparinization of pediatric and high risk adult groups which may increase the risk of bleeding [22].

Contrary to the belief that pediatric transplantation is associated with higher morbidity, our results denied this believe, moreover the thrombotic complication is lower than that of adults. There is a steady decrease in vascular complications over the three decades inspite of training of one urologist every 4 years, that indicate the stability of our training program.

\section{Conclusions}

There is no increased incidence of vascular complications in pediatrics than adult transplants. The vascular complications significantly adverse patient and graft survival in both pediatrics and adults renal transplants. The survival of either graft or patient is comparable between adult an pediatric with or without vascular complications and the subgroups of vascular complications. The thrombotic, stenotic and hemorrhagic events have the same deletrious effect in both patient and graft.

\section{References}

1. Mehrabi A, Wiesel M, Zeier M, Kashfi A, Schemmer P, Kraus T, Buchler MW, Schmidt J: Results of renal transplantation using kidneys harvested from living donors at the university of Heidelberg. Nephrol Dial Transplant. 2004; 19 suppl 4: iv48-54.

2. Emiroglu R, Moray G, Sevmis S, Sozen MH, Bilgin N, Haberal M: Long-term results of pediatric renal transplantation at one center in Turkey. Transplant proc. $2005 ; 37(2): 675-8$

3. Osman Y, Shokeir A, Ali-El-Dein B, Tantawy M, Wafa E, Shehab El-Dein A, Goneim M.: Vascular complications after live donor renal transplantation: study of risk factors and effects on graft and patient survival. J Urol 2003; 169: 859-62.

4. Mehrabi A, Kashfi A, Tonshoff B, Feneberg R, Mehls O, Schemmer P, Kraus T, Wiesel M, Buchler MW, Schmidt $\mathrm{J}$ : Long-term result of pediatric kidney transplantation at the university of Heidelberg: a 35 year single-centre experience. Nephrol Dial Transplant. 2004; 19 suppl 4: iv69-74.

5. Vidne BA, Leapman SB, Butt KM, Kountz SL: Vascular complications in human transplantation. Surgery 1976; 79 : 77-81.

6. Bakir, N., Sluiter, W. J., Ploeg, R. J., van Son, W. J. and Tegzess, A. M.: Primary renal graft thrombosis. Nephrol Dial Transplant, 11: 140, 1996.

7. Nghiem DD: Donor aortoplasty for transplantation of kidney with multiple arteries. J.Urol. 1994; 152: 2055- 6 .

8. Ubhi C, Lam F, Mavor A, Giles G.: Subcutaneous heparin therapy for cyclosporine- immunosuppressed renal allograft recipients. Transplantation. 1989; 48: 886-7.

9. Alkhunaizi A, Olyaei A, Barry J, deMattos A, Conlin M, Lemmers M, Bennett W,: Norman D. Efficacy and safety of low molecular weight heparin in renal transplantation. Transplantation 1988; 66: 533-4.

10. Lundin C, Bersztel A, Wahlberg J, Wadstrom J.: Low molecular weight heparin prophylaxis increase the incidence of lymphocele after kidney transplantation. Ups J Med Sci. 2002; 107: 9-15.

11. Humar A, Johnson E, Gillingham K, Sutherland D, Payne W, Dunn D, Wrenshall L, Najarian J, Gruessner R, Matas A.: Venous thromboembolic complications after kidney and kidney-pancreas transplantation : a multivariate analysis . Transplantation 1998; 65: 229- 34.

12. Yasser Osman, Mohamed Kamal, Shady Soliman, Hussein Sheashaa, Ahmed Shokeir,and Ahmed B. Shehab El- 
Dein.: Necessity of Routine Postoperative Heparinization in Non-Risky Live-Donor Renal Transplantation: Results of a Prospective Randomized Trial. Adult Urology 2007;69(4)647-651.

13. Hashimoto Y, Nagano S, Ohsima S, Takahara S, Fujita T, Ono Y, et al.: Surgical complications in kidney transplantation: experience from 1200 transplants performed over 20 years at six hospitals in central Japan. Transplant Proc. 1996; 28: 1465-7.

14. Kocak T, Nane I, Ander H, Ziylan O, Oktar T, Ozsoy C. Urological and surgical complications in 362 consecutive living related donor kidney transplantations. Urol Int. 2004; 72: 252-6.

15. Fervenza FC, Lafayette RA, Alfrey EJ, Petersen J.: Renal artery stenosis in kidney transplant. Am J Kidney Dis 1998; 31: $142-148$

16. Wong W, Fynn SP, Higgins RM et al.: Transplant renal artery stenosis in 77 patients- does it have an immunological cause? Transplantation 1996; 61:215 -219.

17. O 'Neill WC, Baumgarter DA.: Ultrasonography in renal transplantation. Am J Kidney Dis 2002; 39: 663 -678.
18. Schoenberg SO,Knopp MV,Londy F et al.: Morphologic and functional magnetic resonance imaging of renal artery stenosis:a multireader tricenter study.J Am Soc Nephrol $2002 ; 13: 158-169$.

19. Voiculescu A, Schmitz M, Hollenbeck M, Braasch S, Luther B, Sandmann W, Jung G, Modder U, Grabensee B Management of arterial stnosis affecting kidney graft perfusion: a single-center study in 53 patients. Am J Transplant. 2005; 5(7): 1731-8.

20. Beecroft J, Rajan D, Clark T, Robinette M, Stavropoulos S.: Transplant renal artery stenosis: outcome after percutaneous intervention. J Vasc Interv Radiol 2004; $15: 1407-1413$

21. Kocak t, Nane I, Ander H, Ziylan O, Oktar T, Ozsoy C: Urological and surgical complications in 362 consecutive living related donor kidney transplantations. Urol Int.2004; 72(3): 252-6.

22. Joanna wi.niewska-goryñ1, ewa gorczyca-wi.niewska2, tomasz goryñ1, piotr andziak3, marek durlik.: Treatment of vascular complications after kidney transplantation polish j surgery.2008, 80, 3, 132.138. 